\title{
PATTERN OF ADVERSE CUTANEOUS DRUG REACTIONS IN A TERTIARY CARE HOSPITAL
}

Riswana Nasrin Nazeer Ahamed ${ }^{1}$, Adikrishnan Swaminathan'², Anuradha Priyadarshini ${ }^{3}$, Manu Vidhya Harikumar ${ }^{4}$, Krishnakanth Muralidharan', Murugan Sundaran6, Sudha Rangarajan7, Mahalakshmi Veeraraghavan ${ }^{8}$

${ }_{1}^{1}$ Postgraduate Student, Department of Dermatology, Venereology and Leprosy, Sri Ramachandra University, Chennai.

${ }^{2}$ Associate Professor, Department of Dermatology, Venereology and Leprosy, Sri Ramachandra University, Chennai.

${ }_{3}^{3}$ Assistant Professor, Department of Dermatology, Venereology and Leprosy, Sri Ramachandra University, Chennai.

${ }^{4}$ Senior Resident, Department of Dermatology, Venereology and Leprosy, Sri Ramachandra University, Chennai.

5 Associate Professor, Department of Dermatology, Venereology and Leprosy, Sri Ramachandra University, Chennai.

${ }^{6}$ Professor, Department of Dermatology, Venereology and Leprosy, Sri Ramachandra University, Chennai.

7 Professor, Department of Dermatology, Venereology and Leprosy, Sri Ramachandra University, Chennai.

sProfessor and HOD, Department of Dermatology, Venereology and Leprosy, Sri Ramachandra University, Chennai.

\section{BACKGROUND}

ABSTRACT

An adverse cutaneous drug reaction is an undesirable change in structure and function of skin, its appendages or mucous membrane due to drugs. ${ }^{1}$ The main aim of this study is to detect the pattern of adverse cutaneous drug reaction in a tertiary care hospital.

\section{MATERIALS AND METHODS}

This hospital-based observational study was performed in a tertiary care hospital, SRMC, Chennai, for 1 year from June 2013 to June 2014. For each case, data regarding age and sex of the patient, detailed clinical history, past history and comorbidities, name of suspected drugs, duration between drug intake and onset of reaction, morphology of drug eruption, associated mucosal or systemic involvement were carefully analysed. Different types of drug reactions manifested in the study population were studied and the offending drugs were noted.

\section{RESULTS}

During the one year study period, 30 patients have attended the dermatology outpatient department with cutaneous adverse drug reaction. The mean age of our patients with adverse drug reactions was 57 years. The male-to-female ratio was 7:3. The commonest reaction pattern observed was exfoliative dermatitis (28\%), fixed drug eruption (28\%) followed by toxic epidermal necrolysis (10\%), Stevens-Johnson syndrome (10\%), Bullous fixed drug eruption (10\%) and Urticaria (6\%). Commonest drugs producing reactions were Amoxicillin (23\%), Paracetamol (16\%), Carbamazepine (10 \%) and Phenytoin (10\%).

\section{CONCLUSION}

After a cutaneous drug eruption has been diagnosed and treated, clear information must be provided to the patient regarding his/her drug rash. Early diagnosis and prompt withdrawal of the offending drug and administration of systemic steroids can be lifesaving in cutaneous adverse drug eruption.

\section{KEYWORDS}

SJS- Stevens-Johnson Syndrome, ADR- Adverse Drug Reaction, TEN- Toxic Epidermal Necrolysis.

HOW TO CITE THIS ARTICLE: Ahamed RNN, Swaminathan A, Priyadarshini A, et al. Pattern of adverse cutaneous drug reactions in a tertiary care hospital. J. Evolution Med. Dent. Sci. 2017;6(89):6237-6240, DOI: 10.14260/jemds/2017/1356

\section{BACKGROUND \\ Aim}

An adverse cutaneous drug reaction is an undesirable change in structure and function of skin, its appendages or mucous membrane due to drugs. ${ }^{1}$

Drug eruptions vary in appearance, rapidity of onset, severity and underlying immunological mechanism. They can range from pruritus, maculopapular rash to Stevens-Johnson syndrome or toxic epidermal necrolysis.

'Financial or Other Competing Interest': None.

Submission 03-10-2017, Peer Review 01-11-2017,

Acceptance 07-11-2017, Published 13-11-2017.

Corresponding Author:

Adikrishnan Swaminathan,

$6^{\text {th }}$ Block, 3D Ceebros Park 2A,

Radhakrishnan Salai, Valasaravakkam,

Chennai-600087.

E-mail:adi_krish@yahoo.com

DOI: $10.14260 /$ jemds $/ 2017 / 1356$

The main aim of this study is to detect the pattern of adverse cutaneous drug reaction in a tertiary care hospital.

\section{MATERIALS AND METHODS}

This hospital-based observational study was performed in a tertiary care hospital, SRMC, Chennai for 1 year from June 2013 to June 2014.

In this study, cases of adverse cutaneous drug eruptions were analysed from both the outpatient and inpatient department.

Ethical clearance was obtained from the Institutional Ethics Committee.

\section{Inclusion Criteria}

Patients of all ages and both sexes were included in this study. Any patient presenting with cutaneous reaction after intake of drug. Patients who are willing to participate in this study. 


\section{Exclusion Criteria}

Patients who are not willing to participate in this study.

Patients who developed cutaneous adverse drug eruption following intake of homeopathy, Ayurveda and indigenous medicines were excluded from the study.

For each case, data regarding age and sex of the patient, detailed clinical history, past history and comorbidities, name of suspected drugs, duration between drug intake and onset of reaction, morphology of drug eruption, associated mucosal or systemic involvement were carefully analysed. Different types of drug reactions manifested in the study population were studied and the offending drugs were noted.

\section{RESULTS}

During the one year study period, 30 patients have attended the Dermatology outpatient department with cutaneous adverse drug reaction. The mean age of our patients with adverse drug reactions was 57 years (range: 16 - 77 years). Thirteen patients were in the age group of $20-39$ years $(43 \% ; 13 / 30)$ followed by 11 patients $(36 \%)$ in the age group of 40 - 59 years, 4 patients (13\%) in the age group of $60-79$ years, 2 patients $(6 \%)$ in the age group of $0-19$ years (Figure 1). The male-to-female ratio was 7:3 (Figure 2).

Out of 30 patients, 15 patients required hospitalisation. Of these 15 there were 3 patients with toxic epidermal necrolysis, 3 patients with Stevens-Johnson syndrome, 8 patients with exfoliative dermatitis and 1 patient with fixed drug eruption (Table 1). The commonest reaction pattern observed was exfoliative dermatitis (27\%), fixed drug eruption $(36 \%)$ followed by toxic epidermal necrolysis (10\%), Stevens-Johnson syndrome (10\%), bullous fixed drug eruption (10\%) and urticaria (7\%). Commonest drugs producing reactions were Amoxicillin (23\%), Paracetamol (16\%), Carbamazepine (10\%) and Phenytoin (10\%). Less common drugs producing reactions were ceftriaxone, Pantoprazole, Rabeprazole, Ciprofloxacin, Allopurinol, dapsone, metronidazole, doxycycline and artesunate (Figure 3).

With NSAIDS and antibiotics, the usual time interval observed between the drug intake and the onset of adverse drug reaction was 1 to 2 days, whereas anticonvulsants produce reactions between 1 to 15 days. Four patients had consumed the same drug earlier and developed similar reaction like toxic epidermal necrolysis with amoxicillin, fixed drug eruption with ciprofloxacin, TEN with sodium valproate.

Most of our patients (16/30) had 1\% - 10\% body surface area involvement, 3 patients had $10 \%-30 \%$ body surface area, 3 patients had $30 \%$ - 90\% body surface area, 8 patients had $>90 \%$ body surface area. About $23 \%$ of the patients had mucosal involvement. Systemic manifestations were present in $16 \%$ of patients.

Comorbidities noted in our study were Diabetes mellitus (3 patients), Hypertension (1 patient), Pulmonary tuberculosis (1 patient) and Coronary artery disease (1 patient).

\begin{tabular}{|c|c|c|}
\hline Diagnosis & $\begin{array}{c}\text { No. of } \\
\text { Patients }\end{array}$ & $\begin{array}{c}\text { \% of } \\
\text { Patients }\end{array}$ \\
\hline Toxic epidermal necrolysis & 3 & 10 \\
\hline Stevens-Johnson syndrome & 3 & 10 \\
\hline Exfoliative dermatitis & 8 & 27 \\
\hline Maculopapular rash & 3 & 10 \\
\hline Fixed drug reaction & 11 & 36 \\
\hline Urticaria & 2 & 7 \\
\hline \multicolumn{2}{|c|}{ Table 1 } \\
\hline
\end{tabular}

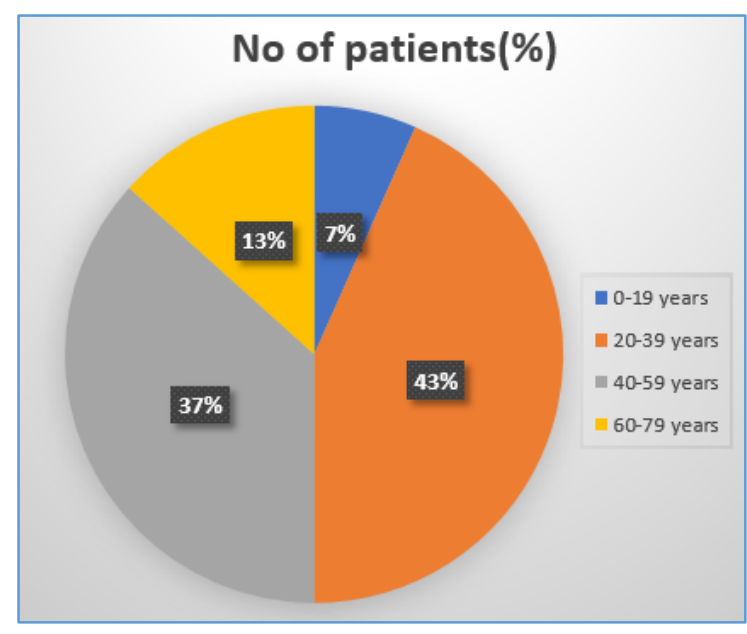

Figure 1. Age Distribution

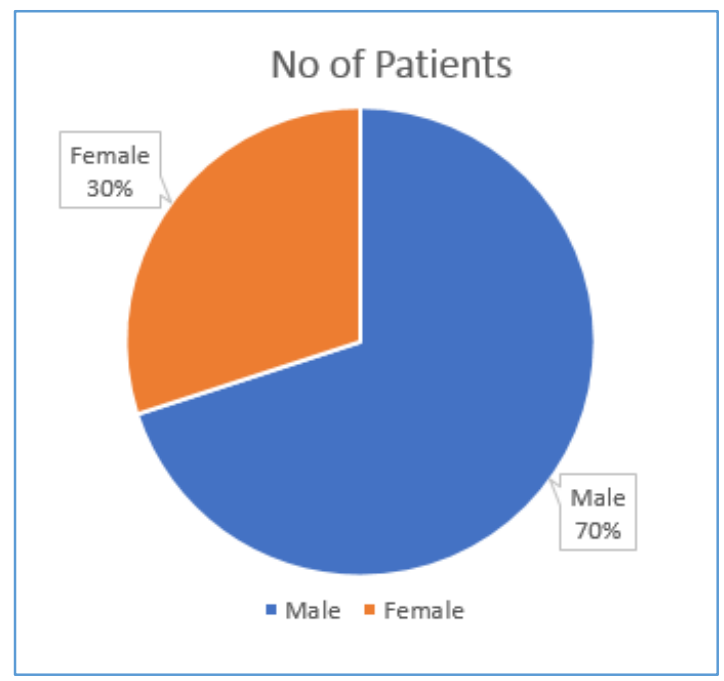

Figure 2. Sex Distribution

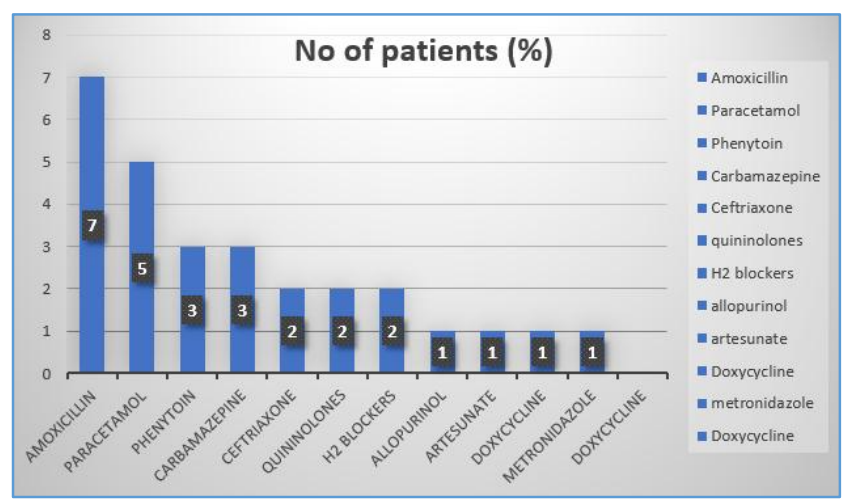

Figure 3. Drugs causing ADR 


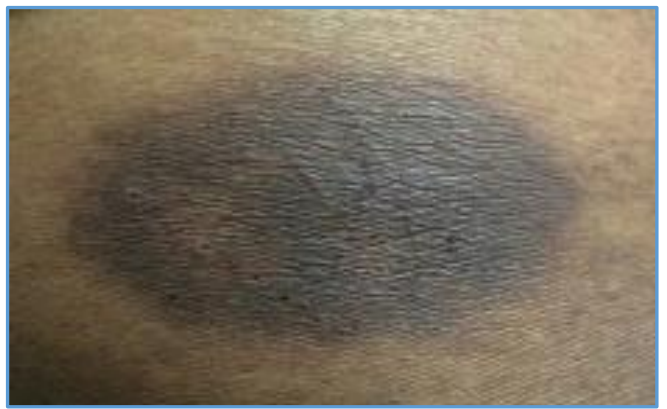

Picture 1. Fixed Drug Eruption

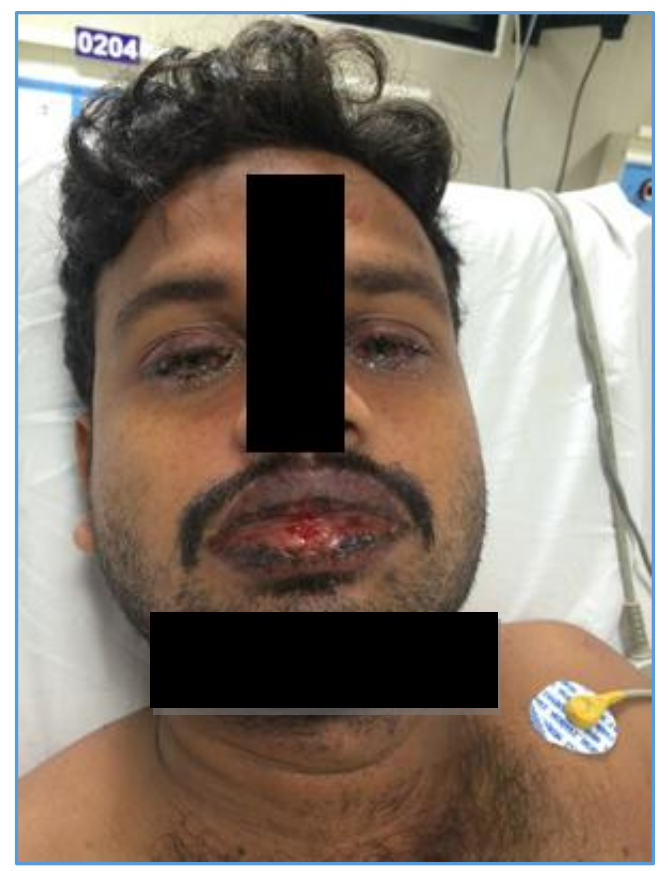

Picture 2. Stevens-Johnson Syndrome

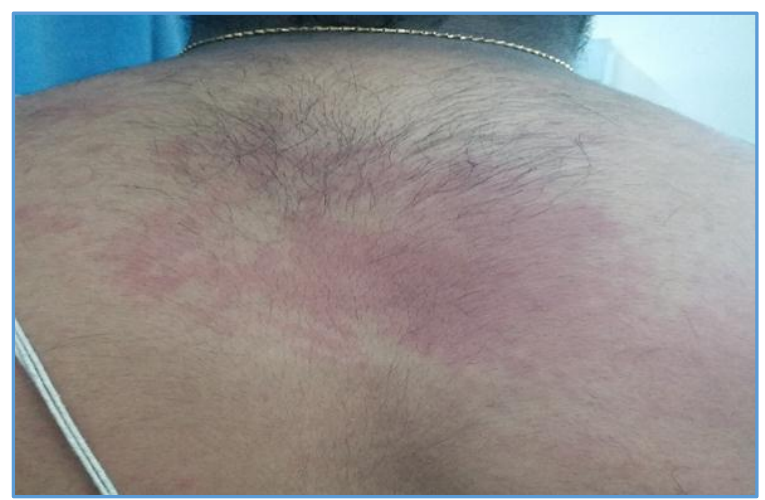

Picture 3. Maculopapular Rash

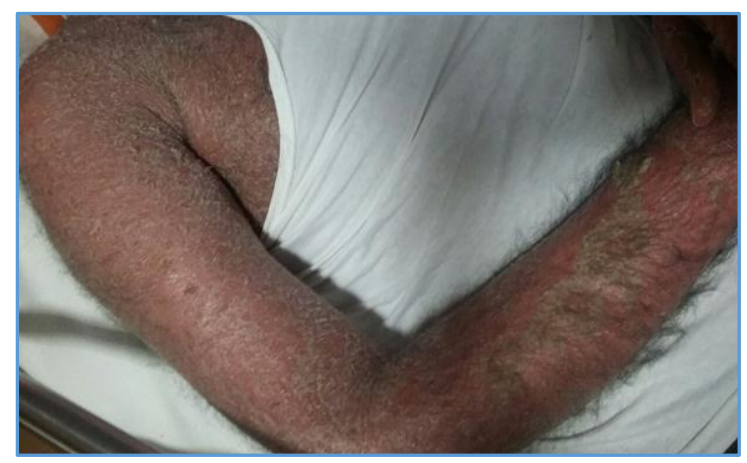

Figure 4. Erythroderma

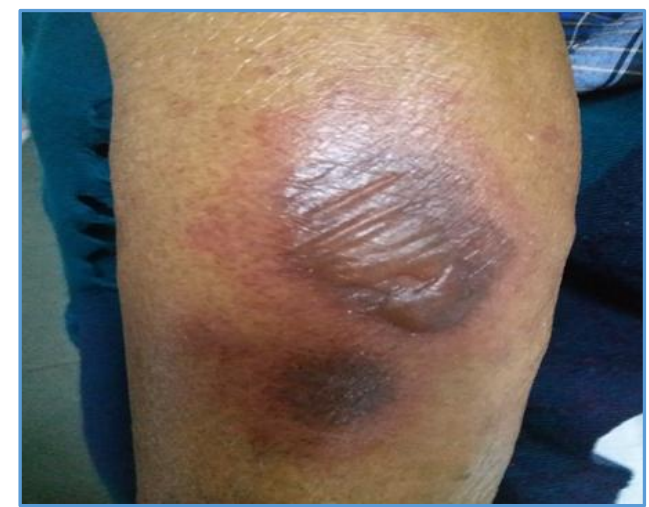

Figure 5. Bullous Fixed Drug Eruption

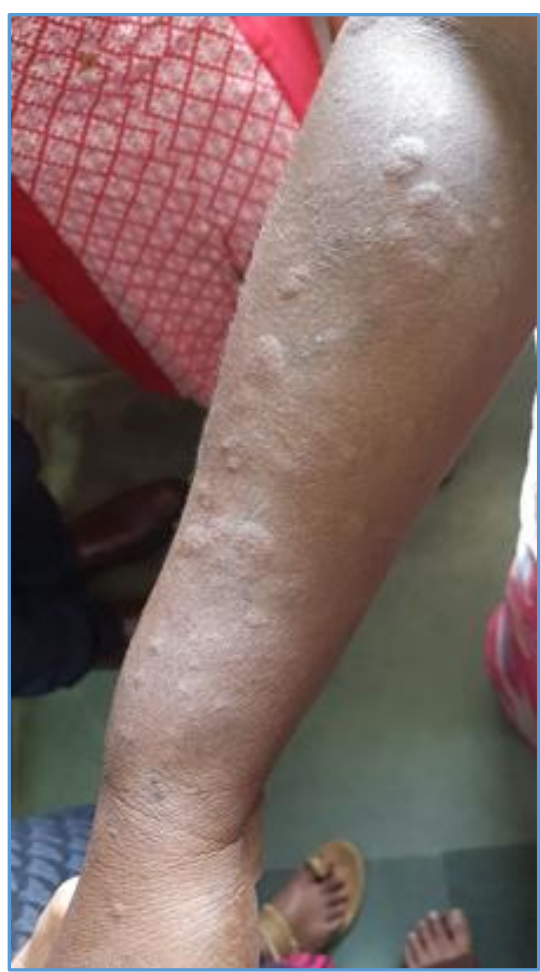

Figure 6. Urticaria

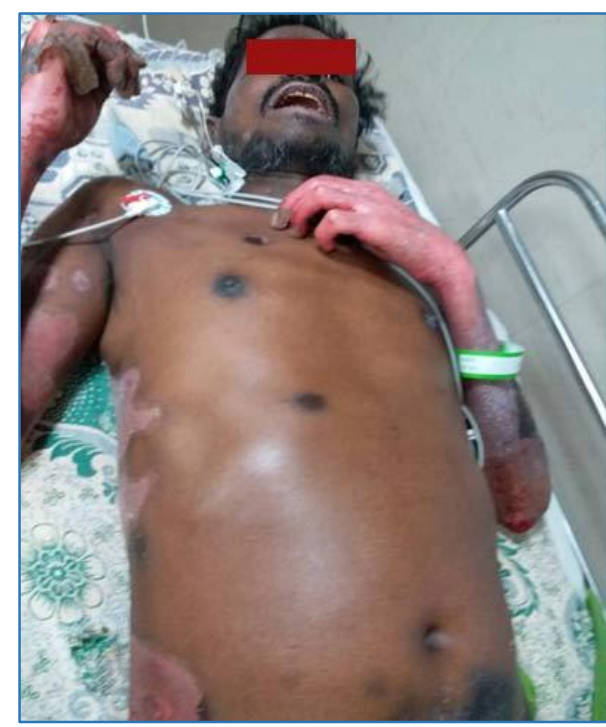

Figure 7a. Toxic Epidermal Necrolysis 


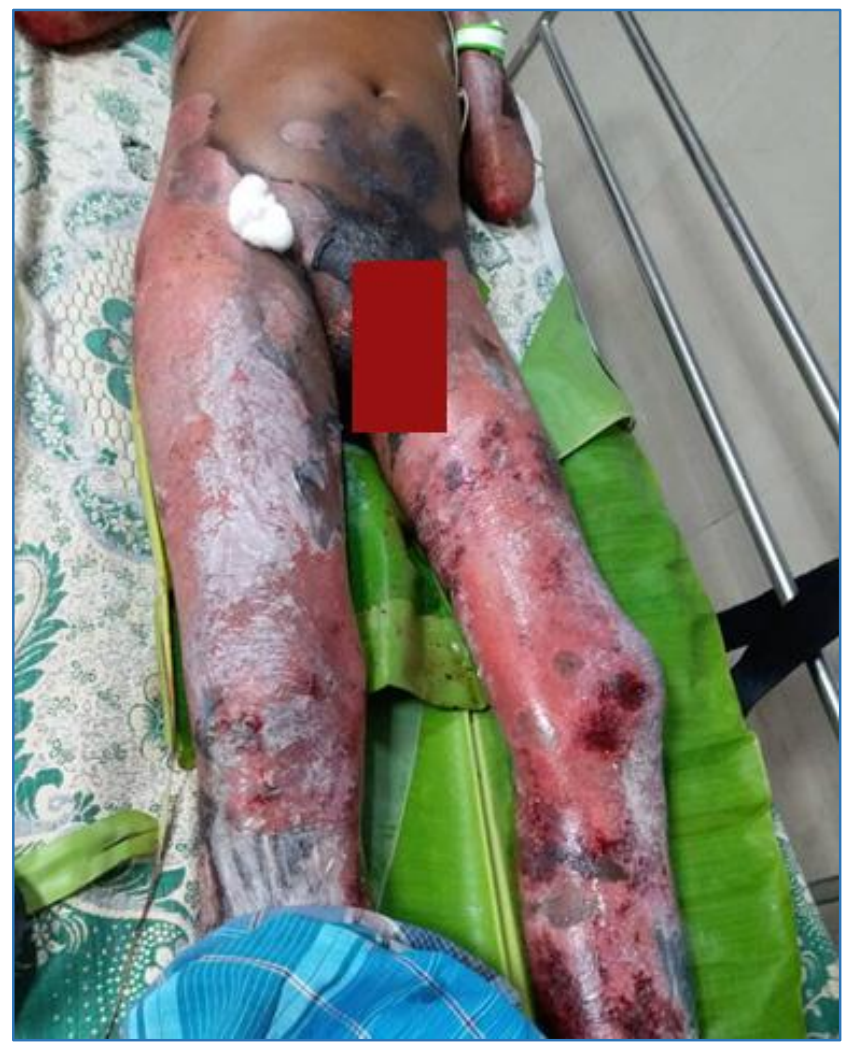

Figure 7b. Toxic Epidermal Necrolysis

\section{DISCUSSION}

Adverse cutaneous drug eruptions have various morphology and distribution.

Adverse cutaneous drug reaction are classified into immunologic and non-immunologic aetiologies. The nonimmunologic aetiologies constitute $(75 \%-80 \%)$ of adverse drug reaction, remaining $(20 \%-25 \%)$ are caused by nonimmunological aetiologies.(2) We conducted a study which observed a male predominance (21 males and 9 females), which was also reported from study conducted by Hiware et al,3 Sasidharanpillai et $\mathrm{al}^{4}$ and Choon SE et al. ${ }^{5}$ The majority of our patients belonged to the 20 - 39 years' age group, which was also observed in another south Indian study.(6)

Of the various types of adverse drug eruptions seen in our study, fixed drug eruption (36\%) and exfoliative dermatitis (27\%) were the most common type of drug eruption followed by Toxic epidermal necrolysis (20\%), Stevens-Johnson syndrome (30\%), Maculopapular rash $(10 \%)$ and Bullous fixed drug eruption (10\%). A study conducted in another tertiary care centre in south India also showed fixed drug eruption to be the most common type of adverse drug eruption.(6)

Commonly, incriminated drugs in our study were amoxicillin (23\%) followed by Paracetamol (16\%), Phenytoin (10\%), Carbamazepine (10\%) and Ceftriaxone (6\%) (Figure 2). Less common drugs causing drug reaction were Dapsone, Allopurinol, Doxycycline, Metronidazole, Ciprofloxacin,
Levofloxacin, Pantoprazole, Rabeprazole and Artesunate each constituting $3 \%$ of patients. A study performed by tertiary care hospital in Turkey ${ }^{7}$ also showed Amoxicillin to be the most common drug causing adverse drug reaction.

Amoxicillin, anticonvulsants and paracetamol were commonly incriminated in severe drug reactions like SJS, TEN and exfoliative dermatitis. Proton pump inhibitors, dapsone, quinolones, artesunate, doxycycline and metronidazole were commonly incriminated in drug reactions like FDE, bullous drug eruption, urticaria and maculopapular rash.

A study performed by Hiware et al(5) and Akpinar et al(7) found that antimicrobials were the most common group causing cutaneous adverse drug reactions.

\section{CONCLUSION}

In recent years, incidence of adverse drug reactions has increased due to increased use of over-the-counter medications without doctor's advice. After a cutaneous drug eruption has been diagnosed and treated, clear information must be provided to the patient regarding his/her drug rash.(8) Early diagnosis and prompt withdrawal of the offending drug and administration of systemic steroids can be life-saving in cutaneous adverse drug eruption. Discontinuation of the culprit drug is the main aspect of the management of adverse drug reaction.

\section{REFERENCES}

[1] Hotchandani SC, Bhatt JD, Shah MK. A prospective analysis of drug-induced acute cutaneous reactions reported in patients at a tertiary care hospital. Indian J Pharmacol 2010;42(2):118-9.

[2] Nayak S, Acharjya B. Adverse cutaneous drug reaction. Indian J Dermatol 2008;53(1):2-8.

[3] Pudukadan D, Thappa DM. Adverse cutaneous drug eruptions: clinical pattern and causative agents in a tertiary care center in South India. Indian J Dermatol Venereol Leprol 2004;70(1):20-4.

[4] Akpinar F, Dervis E. Drug eruptions: an 8-year study including 106 patients at a dermatology clinic in Turkey. Indian J Dermatol 2012;57(3):194-8.

[5] Hiware S, Shrivastava M, Mishra D, et al. Evaluation of cutaneous drug reactions visiting out patient departments of Indira Gandhi Government Medical College and hospital (IGGMC and H), Nagpur. Indian J Dermatol 2013;58(1):18-21.

[6] Sasidharanpillai S, Riyaz N, Khader A, et al. Severe cutaneous adverse drug reactions: a clinicoepidemiological study. Indian J Dermatol 2015;60(1):102.

[7] Choon SE, Lai NM. An epidemiological and clinical analysis of cutaneous adverse drug reactions seen in a tertiary hospital in Johor, Malaysia. Indian J Dermatol Venereol Leprol 2012;78(6):734-9. 